\title{
Erratum to: Citizen Science for Observing and Understanding the Earth
}

Mordechai (Muki) Haklay, Suvodeep Mazumdar, and Jessica Wardlaw

\section{Erratum to:}

Chapter 4 in: P.-P. Mathieu, C. Aubrecht (eds.), Earth Observation Open Science and Innovation, ISSI Scientific Report Series 15, https://doi.org/10.1007/978-3-319-65633-5_4

The original version of Chapter 4 was inadvertently published with an incorrect reference

Reeves S, Sherwood S, Brown B (2010) Designing for crowds. Proceedings of the 6th Nordic conference on human-computer interaction: extending boundaries, pp 393-402

should actually be

Reeves S (2013) Human-computer interaction issues in human computation. In: Michelucci P (ed) Human computation handbook. Springer, New York, pp 411-419

The reference has now been updated. 